\title{
Haemoperitoneum due to ruptured corpus luteum! managed conservatively- 2 case reports and review of literature
}

\author{
Anjum Ara, Renuka Malik*, Veena Ganju Malla
}

Department of Obstetrics and Gynaecology, PGIMER and DR RML Hospital, New Delhi, India

Received: 11 August 2016

Accepted: 06 September 2016

\section{*Correspondence:}

Dr. Renuka Malik,

E-mail: renucam@yahoo.co.in

Copyright: (c) the author(s), publisher and licensee Medip Academy. This is an open-access article distributed under the terms of the Creative Commons Attribution Non-Commercial License, which permits unrestricted non-commercial use, distribution, and reproduction in any medium, provided the original work is properly cited.

\begin{abstract}
Massive or ongoing Haemoperitoneum is an emergency, usually surgical, managed by laparotomy. Haemoperitoneum seen by gynecologists in clinical practice is usually due to ruptured ectopic. Other causes of haemoperitoneum are traumatic rupture of vascular organs like spleen or liver which are managed by general surgeons. Spontaneous haemoperitoneum $(\mathrm{SH})$ due to bleeding corpus luteum secondary to warfarin induced coagulopathy is encountered very rarely. Bleeding complication in warfarin coagulopathy has high mortality up to $10 \%$. Two cases of warfarin induced significant haemoperitoneum, due to bleeding corpus luteum were managed conservatively, with joint consultation with hematologist and cardiologist. Reversal of anticoagulation usually arrests further bleeding and haemoperitoneum got absorbed as in first case or was drained out in second case. No difference in postoperative period was seen in both cases. Laparoscopy or laparotomy may be needed very rarely after haemostatic control. Emphasis is placed on continuous monitoring in HDU/ICU. Patients on anticoagulant therapy can rarely present with life threatening haemoperitoneum, secondary to ruptured corpus luteum Early diagnosis and reversal of anticoagulation can be lifesaving in this condition which carries significant mortality Unlike ruptured ectopic, ruptured corpus luteum causing haemoperitoneum due to warfarin induced coagulopathy can be managed conservatively, as bleeding stops after reversal of anticoagulation. However a strict continuous monitoring of hemodynamic status and hematology investigations in high dependency unit is required. A heightened awareness of these cases is required due to paucity of available reported literature.
\end{abstract}

Keywords: Haemoperitoneum, Warfarin coagulopathy, Corpus luteal hemorrhage

\section{INTRODUCTION}

Haemoperitoneum seen by gynaecologists in clinical practice is usually due to ruptured ectopic, which needs an immediate surgery. Other causes of haemoperitoneum are traumatic rupture of vascular organs like spleen or liver which are managed at laparotomy by general surgeons. Rarely, one encounters haemoperitoneum due to bleeding corpus luteum secondary to warfarin induced coagulopathy, in patients with prosthetic heart valves. Management of such cases needs joint consultation of gynaecologist, cardiologist and haematologist. Surgery is fraught with danger of bleeding and thromboembolism. Bleeding complication in warfarin coagulopathy has high mortality from $3 \%-11 \%$ and also risk of recurrence in $25-$ $31 \%{ }^{1,2}$ After stopping warfarin and reversing anticoagulation with FFP and vitamin K, bleeding usually stops. However warfarin has to be restarted after management of initial crisis and in future, ovulation bleed prevented by ovulation inhibiting drugs like oral pills (OCP) or injectable progestins.

\section{CASE REPORT}

\section{Case report 1}

A 40 year old woman, Para 4 , resident of Rajasthan, was referred from a private nursing home in Jaipur on 14 
January 2015 for further management to our hospital, with a diagnosis of suspected ectopic. As per records, patient gave history of mitral valve replacement done 4 years back in our hospital for which she was taking 7.5 mg warfarin daily. She developed pain abdomen and distension three days prior to reporting to our hospital, for which she consulted a private nursing home. There, an ultrasound was done and haemoperitoneum diagnosed. Her LMP was 14 day back and she used barrier contraceptive. Urine pregnancy test (UPT) done there was negative. Her $\mathrm{Hb}$ was $6 \mathrm{gm} \%$ and she was given 3 units of packed cells (PC) and 2 fresh frozen plasma (FFP) in the nursing home. A paracentesis was done which aspirated blood as per her referral record. Patient was pale though haemodynamically stable upon reporting to our hospital. She also had a 3x3 cm hematoma in Right iliac fossa at the site of paracentesis. Her investigations done in our hospital, revealed an $\mathrm{Hb}$ of $8 \mathrm{gm} \%$, PT INR of 3.2. She was given 2 units of PC with 3 FFP. In pelvic examination uterus was bulky, fullness and tenderness was felt in both fornices. Cervical excitation pain was present. Ultrasound revealed about $800 \mathrm{ml}$ of haemoperitoneum and right adenexal mass of $5 \times 3 \mathrm{~cm}$, with mixed echo texture. Urine pregnancy test was repeated which was found to be negative. She was put on continuous monitoring of vitals. Patient remained haemodynamically stable and next day CT scan was done which was reported as adenexal mass with haemoperitoneum. During a hospital stay of 10 days, her haemoperitoum slowly decreased, as was evident on serial ultrasound monitoring. Warfarin was restarted on day 8 in a lower dose of $4 \mathrm{mg}$ with INR of 2.2 and inj depot Provera was given I/M in dose of $150 \mathrm{mg}$ to prevent further ovulation bleed. Patient continues to be in follow up near her residence in Jaipur.

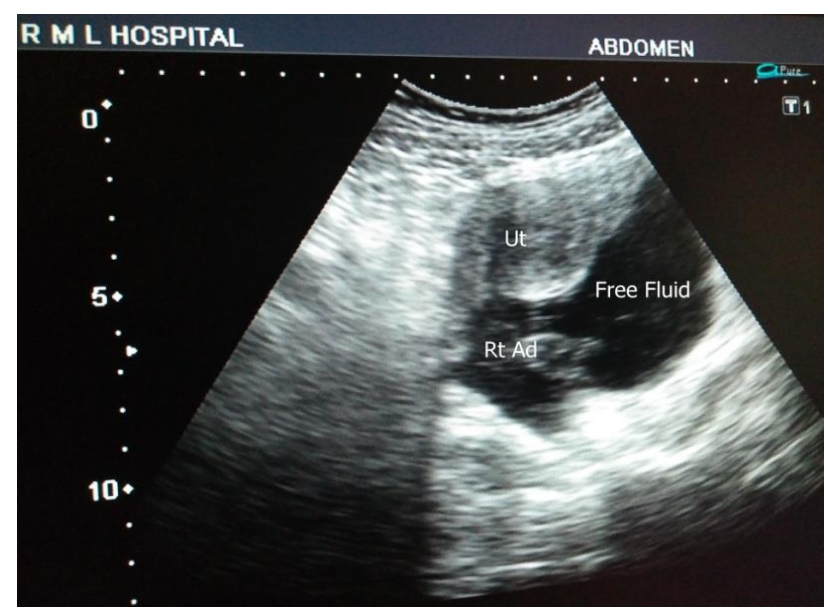

Figure 1: Pelvic USG showing haemoperitoneum with right adnexal mass.

\section{Case report 2}

A 30yrs old female P1, L1 presented in Gynaecology OPD on 6th may 2016 with complaints of pain in abdomen for one day and history of amenorrhea for one and a half month. She was a known case of mitral valve replacement 2 years back and was taking tablet warfarin $4 / 5$ on alternate days. Her LMP was 10 day back and she used barrier contraceptives. On examination, pulse was $110 / \mathrm{min}$ and BP $100 / 60 \mathrm{~mm} \mathrm{Hg}$ and generalized tenderness was present in lower abdomen. In her pelvic examination uterus was normal size and fornices were tender. UPT was negative. ECG showed atrial fibrillation. Pelvic USG findings revealed a right adnexal mass, 4X4 $\mathrm{cm}$, with gross haemoperitoneum, uterus was normal size and all other visceral organs were intact (Figure 1). Pt collapsed on her way back, she was resuscitated and all relevant investigation was sent. Her lab investigation showed $\mathrm{Hb}$ as $5.5 \mathrm{gm} \%$, TLC 7200, INR 5.15 and B HCG was 0.39. She was transfused with 3 units of PC and 6 units of FFP and injection Vit K 10mg i.v was given. As she was high risk in view of immediate laparotomy and her vitals were stable in last 6 hours of admission, a decision for a constant monitoring with need for immediate laparotomy if BP fell was taken. As her vitals improved with all the resuscitative measures, a conservative management continued. Her D2 investigation was $\mathrm{Hb} 7.8 \mathrm{gm} \%$, TLC 6500 and INR 1.51. As her INR was stabilized on D3, two abdominal drains under USG guidance were inserted in lumbar areas and approx. 1800cc of blood mixed fluid was drained (Figure 2). On D4, 72 hrs after admission, she was started on LMWH after cardiac consultation. On D8 both the drains were removed as there was no subsequent drainage and patient was restarted on Tablet Warfarin $2 \mathrm{mg}$. Patient was discharged on Day 10 on Inj. Depot provera. Patient was asymptomatic during her follow up visits.

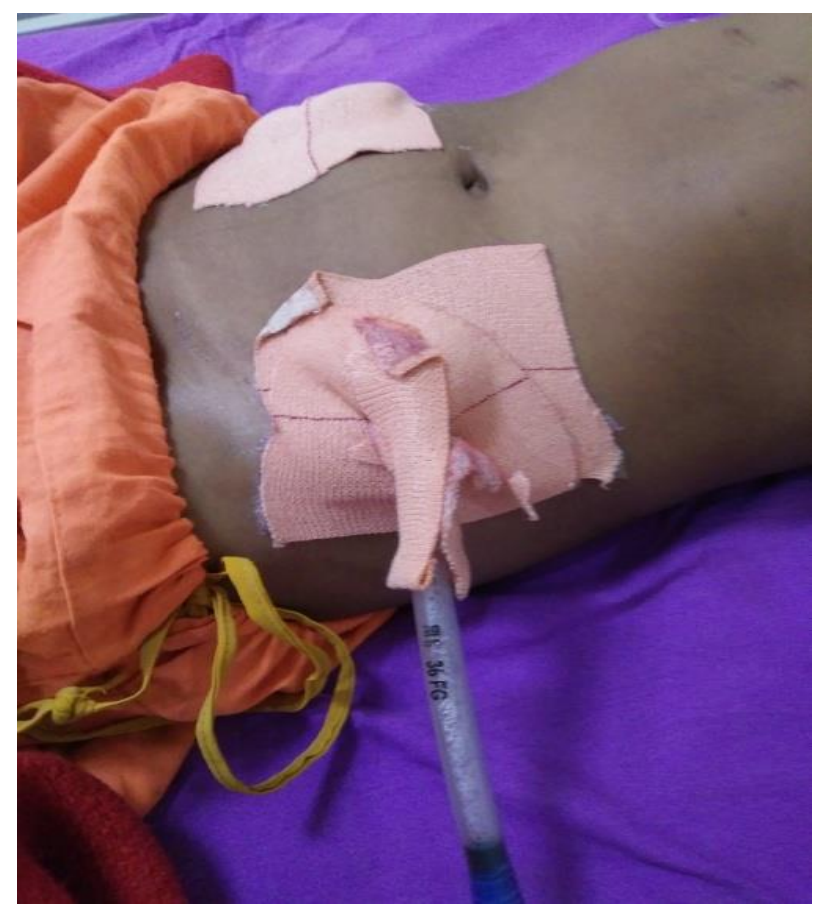

Figure 2: Two drains in both paracolic gutter draining $1800 \mathrm{ml}$ of blood mixed fluid on day 1 , in case 2. 


\section{DISCUSSION}

The clinical basis on which the diagnosis of corpus luteal hemorrhage was made were clinical history of patients being in luteal phase, imaging studies and negative urine b-Hcg, however possibility of ectopic with negative urine pregnancy test are there, although rare. In the first case, which was referred to us when $48 \mathrm{hrs}$ had passed and vitals remained stable signifying arrest of on-going hemorrhage. In second case, we followed the patient strictly in first 24 hours to gather that the hemorrhage stopped with no need for immediate laparotomy. There are various causes of $\mathrm{SH}$ in women of reproductive age group most common being ruptured ectopic, ruptured ovarian cysts and corpus luteum hemorrhage. The formation of the corpus luteum begins with the release of an ovum from a ripe follicle. According to Novak and Woodruff, bleeding does not occur from stigma because it becomes plugged with fibrin. Ovulation is followed by a stage of proliferation or hyperaemia, consisting of follicular collapse and luteinisation of the granulosa layer, which is devoid of blood vessels. The lumen of the corpus still contains no blood. The stage of vascularization then occurs: the granulosa layer is penetrated by blood vessels that pass vertically towards the cavity of the corpus luteum, filling the cavity with blood. If this corpus luteum hematoma ruptures, intraperitoneal hemorrhage may occur, especially if the woman's clotting mechanisms are depressed by anticoagulant therapy. ${ }^{3}$

Warfarin is a lifesaving drug; the incidence of bleeding during its use is stated to be between $2 \%$ and $13 \%$. Bleeding may occur intra, extra-peritoneally or retroperitoneally. The most important risk factor for hemorrhage in users of VKAs is the intensity of the anticoagulant effect Studies indicate that with a target INR of $>3.0$, the incidence of major bleeding is twice as large as in studies with a target INR of 2.0-3.0. ${ }^{4}$ USG and CT examination are useful in diagnosing $\mathrm{SH}$ confirming the site of bleed in patients. USG can be used to monitor the progress. The spectrum of attenuation values of abdominal fluid will direct to the diagnosis of hemoperitoneum. Peritoneal fluid typically shows higher attenuation values near the source of bleeding; these parameters progressively increase from the upper abdomen to the parietocolic gutters, where the pelvis becomes hyper dense (60-65 HU) The area with the highest attenuation values is defined as "sentinel clot" and it indicates the source of bleeding On CT examination, corpus luteum usually appears like a wellcircumscribed unilocular adnexal lesion, rarely bilocular. The cyst walls appear slightly thickened $(<3 \mathrm{~mm})$ and show a characteristic inhomogeneous contrast enhancement after administration of contrast medium due to increased vascularity. The cystic content is mixed with a high attenuation component (45-100 HU) and in some cases it presents a "fluid-fluid haematocrit" level Contrast-enhanced CT may be helpful in excluding other intra-abdominal diseases (e.g., ruptured hepatic adenoma) that can cause hemoperitoneum in the young female patient. $^{4-7}$

A standard protocol is not reported in literature for the management of SH. Historically the treatment of corpus luteum hemorrhage was exclusively surgical, laparotomy or Laparoscopy and suturing, diathermy or wedge resection or even oophorectomy and salpingooophorectomy. A conservative approach is reported in a few case reports of late. ${ }^{6,8,11,12,14}$ In either case the treatment targets at preserving ovarian function as well as at eliminating the source of bleeding. The products that can be used to restore haemostatic parameters and to stop hemorrhage in the case of critical bleeding due to warfarin include Plasma Cell Concentrate (PCC), FFP, and vitamin $\mathrm{K}$. When the patient is haemodynamically stable (systolic BP $>90 \mathrm{mmHg}$ ) with hemoglobin values that keep being constant over 4-6 hours of monitoring, a conservative approach can be tried if diagnosis of corpus luteal hemorrhage is certain. Besides discontinuing vitamin $\mathrm{K}$ antagonists, PCC should be administered immediately in association with $10 \mathrm{mg}$ vitamin $\mathrm{K}$ supplement given I/V (grade C, level 3). FFP should only be used when PCC are not available (grade B, level 2), as in India. The use of recombinant activated factor VII (rFVIIa) is not recommended (grade C, level 3). Subcutaneous and intramuscular administration of Vitamin $\mathrm{K}$ should be avoided. After the administration of $\mathrm{I} / \mathrm{V}$ vitamin $\mathrm{K}$, within $2 \mathrm{~h}$, the INR will start to drop and will be completely normalized within $12-16$ hours. The recommended dose of FFP is $15 \mathrm{~mL} / \mathrm{kg}$, but attention must be paid to the risk of volume overload. rFVIIa is not recommended for reversal of anticoagulation. This clotting factor is expensive than PCC in and can cause thromboembolism. PCC cost less than rFVIIa, effect is immediate, volume of infusion is small and therefore there is no fluid overload, they are considered the treatment of choice for rapid reversal of oral anticoagulation. ${ }^{6,8,10,13,14}$ However, PCC are not available in India. Consideration is also given to inhibiting ovulation in future and preventing ovulation bleed by use of OCP or progestins. Desogestril, depot provera and OCP are useful in inhibiting ovulation. When desogestrel is administered at a dose of 60-75 $\mu \mathrm{g} / \mathrm{day}$, ovulation is inhibited completely compared to levonorgestrel 30 $\mu \mathrm{g} / \mathrm{day}$, which prevents ovulation in only $40 \%$ of cycles. $^{15-17}$

Informed consent form was taken from patients for publication of case and images.

\section{CONCLUSION}

Women of reproductive age group on oral anticoagulants presenting with acute abdomen and haemoperitoneum, may mimic various etiologies and corpus luteal hemorrhage should be considered as a possibility. A conservative management with Packed Cell, FFP, Vit K, and withholding warfarin, can help in homeostasis. Patient should be restarted on warfarin after the acute 
phase and also given OCP or POP for preventing ovulation associated bleeding in future.

Funding: No funding sources

Conflict of interest: None declared

Ethical approval: Not required

\section{REFERENCES}

1. Tresch DD, Halverson G. Ovarian (corpus luteum) hemorrhage during anticoagulation therapy. Ann int med. 1978;88(5):642-6.

2. Stenchever M. Comprehensive gynecology. 5-th edition. USA, Mosby. 2007. pp. 460-461.

3. Novak ER, Woodruff JD. Novak's Gynecologic and Obstetric Pathology: With Clinical and Endocrine Relations, 7th ed, Philadelphia, Saunders. 1974. pp. 335.

4. Saour JN, Sieck JO, Mamo LA, Gallus AS. Trial of different intensities of anticoagulation in patients with prosthetic heart valves. $\mathrm{N}$ Engl J Med. 1990;322(7):428-32.

5. Crétel E, Cacoub P, Gompel A. Ovarian hemorrhage with hemoperitoneum leads to complication of oral treatment using indirect anticoagulant administered by the oral route. La Revue de Médecine Interne. 2000;21:428-34.

6. Gupta A, Gupta S, Manaktala U. Conservative management of corpus luteum haemorrhage in patients on anticoagulation: a report of three cases and review of literature. Arch Gynecol Obstet. 2015;291(2):427-31.

7. Fiaschetti V, Ricci A. Hemoperitoneum from Corpus Luteal Cyst Rupture: A Practical Approach in Emergency Room Case Rep Emerg Med. 2014:252657.

8. Ho WK, Wang YF, Wu HH, Tsai HD, Chen TH, Chen M. Ruptured corpus luteum with hemoperitoneum: case characteristics and demographic changes over time. Taiwan J Obstet Gynecol. 2009;48:108-12.
9. Barillari G, Pascal S. Emergency reversal of anticoagulation: from theory to real use of prothrombin complex concentrates. A retrospective Italian experience Blood Transfus. 2012;10(1):87-94.

10. Gupta N, Dadhwal V, Deka D, Jain SK, Mittal S. Corpus luteum hemorrhage: rare complication of congenital and acquired coagulation abnormalities. The Journal of Obstetrics and Gynaecology Research. 2007;33(3):376-80.

11. Tanaka T. Non-operative Management of Idiopathic Ovarian Hemorrhage with Massive Intraabdominal Hemorrhage .Osaka City Medical Journal. 1997;43:7-14.

12. Murao H, Kinjyo, K. Demura T. Conservative therapy for corpus luteum hemorrhage, a review of 116 cases. Clin. Gynecol. Obstet. 1994;48:568-72.

13. Fong YI, Chua HW, Singh C. Diagnostic Dilemma: Acute Abdomen from Ruptured Corpus Luteum Requiring Surgical Intervention in Young Women. Thai Journal of Obstetrics and Gynecology. 2013;21:80-6.

14. Sikka P, Joshi B, Aggarwal N, Suri V. Corpus Luteal Hemorrhage in Coagulopathy; A Case Report with Review of Treatment Modalities. Austin J Obstet Gynecol. 2015;2(2):1038.

15. Sonmezer M, Atabekoglu C, Cengiz B, Dokmeci F, Cengiz SD. Depot medroxyprogesterone acetate in anticoagulated patients with previous hemorrhagic corpus luteum. Eur J Contracept Reprod Health Care. 2005;10:9-14.

16. Payne JH, Maclean RM, Hampton KK, Baxter AJ and Makris M. Haemoperitoneum associated with ovulation in women with bleeding disorders: the case for conservative management and the role of the contraceptive pill. Haemophilia. 2007;13:93-7.

17. Rice CF, Killick SR, Dieben $\mathrm{T}$ and Coelingh Bennink H. A comparison of the inhibition of ovulation achieved by desogestrel 75 micrograms and levonorgestrel 30 micrograms daily. Hum Reprod. 1999;14:982-5.

Cite this article as: Ara A, Malik R, Malla VG. Haemoperitoneum due to ruptured corpus luteum! managed conservatively- 2 case reports and review of literature. Int J Reprod Contracept Obstet Gynecol 2016:5:3622-5. 